\title{
Los negocios y el interés frente a la moral y el des- interés. Una visión a contracorriente de la ética empresarial
}

\author{
Miguel Ruiz Muñoz'
}

La cosa tiene un nombre: ética económica. Y tiene un misterio: sus reglas. Pero lo que yo supongo es que esto pertenece a ese tipo de fenómenos (como la razón de Estado o la cocina inglesa) que se presentan en la forma de un misterio porque tienen que mantener oculto el hecho de que no existen en absoluto (Niklas Luhmann).

Resumen: El presente trabajo constituye una reflexión crítica sobre la RSC/RSE (Responsabilidad Social Corporativa / Responsabilidad Social Empresarial). Como argumento previo se pone de manifiesto la estrecha conexión entre la RSC/RSE y la ética empresarial. Sentado lo anterior el argumento fundamental del trabajo es la incompatibilidad entre la vida de los negocios, necesariamente interesada, y la moral que debe estar presidida por el desinterés. Y se llega a este convencimiento tanto de la mano de las ideas kantianas como de las de A. Smith. De modo que a juicio del autor difícilmente se puede hablar de que la ética empresarial pueda constituir una fuente de beneficios, ni tampoco que se le pueda considerar como la gran regeneradora de la confianza pérdida en los mercados, porque la moral no es un buen instrumento para gobernar la empresa, sino que por el contrario puede ser más bien causa de confusión en la misma. Es la Ley el cauce adecuado para introducir criterios morales en la gestión de la empresa. Desde un punto de vista jurídico-societario, la RSC/RSE y los planteamientos éticos que conlleva no son nada fáciles de integrar en la estructura jurídico-organizativa propia del Derecho de sociedades. Especialmente porque la cláusula de "interés social", que sería la vía de posible entrada de la RSC/RSE en la compañía, se acabaría convirtiendo en un cajón de sastre donde todo cabe, lo que daría lugar entre otras cosas a que dicha cláusula perdiese toda su funcionalidad normativa.

' Departamento de Derecho mercantil. Universidad Carlos III, Madrid. 


\section{Note critical for Corporate Social Responsibility (CSR/RSE)}

Abstract: This work is a critical reflection on CSR/RSE. As a previous argument is highlighted the close connection between CSR/RSE and the business ethics. Sitting above, the fundamental argument of this paper is the incompatibility between the business life necessarily based on interest, and morality that should be chaired by the disinterest. This conviction is reached both by the hand of Kant's ideas as those of A. Smith. So by the author's opinion is hardly speak of that business ethics can be a source of benefits, or that business ethics can regenerate the lost confidence in the markets, because morality is not a good instrument to govern the company, but instead may be more a source of confusion in it. Law is the proper course to introduce moral criteria in the management of the company. From a legal corporate standpoint, CSR/RSE and the ethical considerations involved are not easy to integrate into the own organizational structure of Company Law. Especially because the "social interest" clause, which would be the possible entry pathway of CSR/ RSE in the company, eventually transforms in a catch-all where everything fits, which would lead to such a clause would lose all of its functionality as regulation.

Keywords: Corporate Social Responsibility, Social Responsibility of the Company, Business Ethics, overconfidence, distrust, corporation, corporate interest, liability of directors, stakeholders, shareholders.

\section{Les affaires et l'intérêt en face de la morale et l'altruisme. Une vue en amont de l'éthique des affaires}

Résumé: Cet article constitue une réflexion critique sur la Responsabilité sociale de l'entreprise (RSE / CSR). Comme un argument préalable, le travail met en évidence le lien étroit entre la RSE et l'éthique des affaires. Una fois établie cette idée, I' argument fondamental de ce document est l'incompatibilité entre la vie de l'entreprise, nécessairement intéressée, et la morale qui doit être présidée par le désintérêt. On atteint cette conviction en suivant les idées kantiennes à la fois que celles d'A. Smith. Ainsi, selon l'auteur, on peut guère parler de ce que l'éthique des affaires puisse être une source de bénéfices, ni qu'elle ne puisse être considérée comme la grand restauratrice de la confiance perdue dans les marchés, parce que la morale n'est pas un bon instrument pour gouverner la société, mais au contraire, elle peut être source de confusion. La loi est le canal approprié pour introduire des critères moraux dans la gestion de l'entreprise. D'un point de vue juridique, les considérations d'entreprise et la RSE ne sont pas faciles à intégrer dans la structure juridique et organisationnelle du droit des sociétés. Surtout parce que la cause de l'intérêt social, ce qui serait la voie d'entrée possible de la RSE dans l'entreprise, finirait par devenir une caisse de tailleur, où tout se tient, ce que provoquerait entre d'autres choses la perte pour cette clause de toutes ses fonctionnalités normatives.

Mots-clé: Responsabilité sociale de la compagnie, Responsabilité sociale de l'entreprise, éthique des affaires, excès de confiance, méfiance, compagnie, intérêt social, responsabilité des gestionnaires, groupes d'intérêt. 
Palabras clave: Responsabilidad social corporativa, Responsabilidad social empresarial, ética empresarial, exceso de confianza, desconfianza, sociedad mercantil, interés social, responsabilidad de administradores, grupos de interés, accionistas.

Fecha de recepción: 20 de noviembre de 2013.

Fecha de admisión definitiva: 13 de febrero de 2014 .

\section{Introducción: ética empresarial y RSC/RSE}

Cuando uno mira las cosas con cierta perspectiva histórica siempre aparecen las paradojas, que nos sorprenden y nos hacen ver como unas mismas ideas han podido ser utilizadas para lo uno y para su contrario. Sin retrotraernos mucho en el tiempo, en algo más de un siglo, lo que va de finales del XIX al momento presente, hemos pasado de un reproche más o menos generalizado al mercado por inmoral, especialmente por influencia de las teorías marxistas, pero también con viejos antecedentes de raíz teológico-escolástica, ${ }^{2}$ a una nueva visión más reciente de un mercado moralizado, en este caso por obra de la ética empresarial o ética económica y muy especialmente por obra de la denominada responsabilidad social corporativa o responsabilidad social de la empresa.

Como se ve un mismo instrumental argumental, la moral o la ética, ha sido utilizado desde fuera para denigrar al mercado, por inmoral, y desde dentro para legitimarlo. Respecto al reproche tradicional de inmoralidad se ha basado en la motivación del beneficio, porque fomenta el egoísmo y la avaricia y eleva el vicio a la categoría de virtud. ${ }^{3}$ Esto último nos lleva a uno de los planteamientos más perversos del utilitarismo, el desarrollado por Mandeville en La fábula de las abejas, con un perturbador subtítulo: los vicios privados hacen la prosperidad pública. ${ }^{4}$ Un planteamiento del que claramente se distancia A. Smith a pesar de su proxi-

2 Cfr. A. Escohotado (2008) Los enemigos del comercio. Historia de las ideas sobre la propiedad privada, I, Madrid, pp. 290-291.

${ }^{3}$ Cfr. H. B. Acton (2002) La moral del mercado [1971], Madrid, 22002, p. 27.

${ }^{4}$ B. MANDEVILIE (1997) La fábula de las abejas o Los vicios privados hacen la prosperidad pública [1729], Madrid, FCE. 
midad. ${ }^{5}$ Pero lo verdaderamente importante es ver que no hay nada de inmoral en la actividad mercantil, en el mercado o si se quiere en el sistema capitalista. ${ }^{6}$ Pues al final, como el mismo A. Smith puso de manifiesto, para la búsqueda de la rentabilidad o del beneficio basta con hacer un balance de los costes de materiales, del precio del dinero y de los costes laborales de una empresa bajo unas determinadas condiciones de mercado. ${ }^{7}$

Y por otro lado, el fenómeno más moderno del recurso a la moral por el mercado, especialmente en tiempos de crisis. Y esto es lo que sucede hoy día con la ética empresarial o económica y la RSC/RSE, que se nos presentan con un efecto moralizador de la actividad empresarial. Como es sabido, existe una preocupación universal por el comportamiento de los directivos empresariales, cosa que no está mal ni está de más, todos diríamos que siempre ha sido necesaria y mucho más en los tiempos que corren. El problema es que dicha preocupación no se refiere tanto a lo que es legal o ilegal, sino más bien a lo que es correcto o incorrecto, a lo que afecta a las actitudes, a los valores, a la ética en suma. Y esta preocupación ha encontrado respuesta en la forma de códigos, de recomendaciones - "normas blandas" que promueven el buen gobierno de las empresas. ${ }^{8}$ Más concretamente, primero, con el desarrollo del denominado Gobierno Corporativo (Corporate Governance) y, en un segundo momento, con la Responsabilidad Social Corporativa o Responsabilidad Social de la Empresa, que pasaría a integrarse dentro del primero.

Sobre la idea o el concepto de RSC/RSE no es algo que esté muy claro. No obstante, en términos muy generales se puede decir que se trata de un conglomerado de valores y de buenas intenciones. Y más concretamente, lo que se pretende es que la empresa atienda no sólo los intereses de los accionistas (shareholders), esto es, los intereses de los propietarios de la empresa, sino a todos los intereses afectados

${ }^{5}$ Cfr. M. SANTOS Redondo (1997) Los economistas y la empresa. Empresa y empresario en la historia del pensamiento económico, Madrid, p. 43.

${ }^{6}$ Cfr. A. Comte-Sponville (2004) El capitalismo, ¿es moral?, Barcelona, especialmente pp. 23-56 y 83-102.

7 Cfr. N. LuHmann (2013) "La ética económica, ¿es una ética?", en N. LuHmann (2013) La moral de la sociedad, Madrid, pp. 189-190.

${ }^{8}$ Cfr. A. OlCESE SANTONJA, director (2007) La Responsabilidad Social de la Empresa (RSE). Propuesta para una nueva economía de la empresa responsable y sostenible, Madrid junio 2007, Real Academia de Ciencias Económicas y Financieras, pp. 35ss. (especialmente p. 46). Consultable en www racef.es. 
por la actividad empresarial (stakeholders), además de los accionistas o propietarios, a los empleados, proveedores, consumidores, acreedores, competidores, comunidades locales y la sociedad en su conjunto. O en términos más sencillos: "La tendencia a exigir de las empresas -principalmente de las grandes corporaciones, sociedades cotizadas o multinacionales- una <conducta> que preste atención a intereses distintos de los de sus accionistas y directa o indirectamente vinculados con su actividad." de sociedades, es la recuperación de la vieja idea institucional del interés social pluralista de la sociedad anónima, una idea que en los últimos años ha estado arrinconada por la imperante visión contractualista de carácter monista. ${ }^{10}$

Pues bien, lo más relevante para nosotros es la estrecha conexión entre la ética y la RSC/RSE, de manera que la primera se constituye en el núcleo central de la segunda, como así lo ponen de manifiesto tanto los desarrollos teóricos, como los numerosos documentos internacionales, nacionales y de todo tipo que se ocupan de esta última. " Lo que ha dado lugar a que se hable de que "la ética empresarial es una fuente de beneficios", de que "la ética vende", que "la ética es eficiente" o que "ser ético es rentable". Y de este recurso a la moral, o a la ética, por la empresa se nos pretende hacer ver que redundará en un beneficio para la misma. La ética se internaliza, o dicho de otro modo, la ética se utiliza interesadamente. Algo que no es posible. Y es aquí, por tanto, donde surgen nuestras dudas, porque no parece correcto hablar de que el recurso a ciertos principios éticos por los directivos de empresa redundarán en beneficio del interés de su propia empresa. Y no es así porque la moral es en sí misma desinteresada, de modo que todo comportamiento interesado carece de valor moral

"Vid. J. Sánchez-CAlero Guilarte (2006) voz "Responsabilidad social corporativa", en C. Alonso Ledesma (2006) Diccionario de Derecho de Sociedades, Madrid, p.1023.

10 Cfr. G. Esteban Velasco (2005) "Interés social, buen gobierno y responsabilidad social corporativa (algunas consideraciones desde una perspectiva jurídico-societaria), en AA. VV. (2005) Responsabilidad social corporativa. Aspectos jurídico-económicos, Castellón de la Plana, pp. 13 ss., especialmente pp. 25 ss.

11 Una primera aproximación a esta documentación puede verse en M. RUIz MUÑOz (2012) "Un apunte crítico sobre la Responsabilidad Social corporativa (RSC/RSE)": RdS 38, enero-junio, pp. 155ss., especialmente p. 158. Cfr. también H. Ancos Franco y Y. Sánchez-URán AzAÑa (2013) "Marco normativo de la responsabilidad social empresarial", en Y. SÁNCHEZ-URÁN AzAÑA director (2013) Responsabilidad social de las organizaciones, Madrid, pp. 27ss. 


\section{El interés en los negocios y el desinterés en la moral: los actos de doble motivación no tienen valor moral.Kant,Schopenhauer, Adam Smith y Amartya Sen}

Sin perivicio de lo que digamos enseguida, hay que anticipar que hay datos para la sospecha, pues como tiene escrito G. Peces-Barba," "Cuando una moralidad privada coincide siempre con los intereses de su titular, hay grandes motivos para sospechar que esa persona carece de moralidad." O también en términos muy parecidos como se pronuncia Howard Gardner, cuando después de decirnos que el rasgo cardinal de una postura verdaderamente ética es el sentido de la responsabilidad, que lo podemos equiparar al sentido del deber, nos hace un salvedad importante:

es fácil ser ético cuando se anteponen los propios intereses, la prueba de fuego de la ética se da cuando los propios intereses se contraponen al proceder adecuado en una determinada función. La prueba de la ética es la responsabilidad, al margen de los intereses particulares. ${ }^{13}$

En definitiva, como vemos, se establece claramente la correlación entre la moral y el desinterés, por un lado, y los negocios y el interés, por otro.

Lo anterior, promover que la ética es rentable, significa que la utilización de la moral es en todo caso una utilización interesada, algo que no es propio de la misma, porque lo propio de la moral es el desinterés. De esta manera lo que se produce es una grave confusión de planos o de órdenes, se confunden el orden técnico-empresarial o económico con el orden moral, cuando ambos responden a reglas o principios distintos. ${ }^{14}{ }^{2}$ La ética empresarial, y su principal baluarte actual, como es la RSC/RSE, no deja de ser una moda, ${ }^{15}$ que como tal está sometida al

${ }^{12} \mathrm{G}$. PeCES-BARBA (1993) Ética, Política y Derecho: El paradigma de la modernidad (Discurso de recepción), Madrid, Real Academia de Ciencias Morales y Políiticas, pp. 11-46, especialmente 28-31.

${ }^{13}$ Vid. H. GARDNER (2011) Verdad, belleza y bondad reformuladas. La enseñanza de las virtudes en el siglo XXI (Truth, Beauty, and Goodness Reframed), Barcelona, p. 106.

${ }^{14}$ Vid. A. ComTe-Sponville (2004), El capitalismo, ¿̇es moral?, op. cit., pp. 57ss.

${ }^{15}$ Cfr., entre nuestros juristas, J. M. EMBID IRUJo (2004) "La responsabilidad social corporativa ante el Derecho mercantil": Cuaderno de Derecho y Comercio, 24, pp. 11 ss., especialmente p. 42, donde nos dice: "Como todas la modas, y la RSC, en nuestros días, merece gozar de ese calificativo, encontramos en el propósito, tan generalizado, de configurar empresas "socialmente responsables" una subordinación a los imperativos del momento, sin duda, pero también una forma de encadenar ciertas pretensiones 
fenómeno del eterno retorno, y que por la misma razón es generadora de confusión ${ }^{16}$ y de inseguridad, lo que sin duda no se compadece bien con la necesaria seguridad de los tráficos mercantiles. Y hay que recordar aquí que la confusión no es nunca generadora de confianza, por lo que resulta más que contradictorio que, como suele suceder, se pretenda justificar la ética empresarial desde la necesidad o la conveniencia de aportar mayor confianza a la actividad empresarial. ${ }^{17}$ Pero además, hay que decir que hablar de moda en el mundo de las ideas resulta cuando menos extravagante, porque las ideas dejan de ser tales para convertirse en simples costumbres y conformismos. Pues como dice H. B. Acton: "Es evidente que una sociedad en la que las ideas se aceptan porque están de moda necesita un cambio profundo". ${ }^{18}$

Decimos que lo propio de la moral es el desinterés, pero aún así hay que continuar la indagación y preguntarse por los actos de doble motivación, esto es, cuando en un mismo sujeto y acto coinciden un interés propio y un interés ajeno. ¿Qué sucede en estos casos? $\dot{2}$ Estamos ante actos interesados? Y que por tanto no pueden ser valorados moralmente. O por el contrario ¿̇estamos ante actos desinteresados? En cuyo caso la valoración moral es valiosa. O dicho de otro modo, ¿qué es lo que debe primar en los actos de doble motivación: el interés o el desinterés?

Pues bien, es cierto que se pueden producir coincidencias de motivaciones morales y de otro tipo, y precisamente en estos supuestos de doble motivación, para intentar resolver esta importante cuestión acudimos al gran filósofo de la moral Immanuel

sociales con planteamientos más clásicos que se creían, hasta hace poco, plenamente superados". También, J. SánChez-CALERO GUILARTE (2006) voz "Responsabilidad social corporativa", en C. Alonso LEDESMA (2006) Diccionario de Derecho de Sociedades, Madrid, pp. 1023ss., especialmente p. 1025, en que se dice que "La RSC se ha convertido en una genuina moda, sobre la que confluyen todo tipo de iniciativas y de ideologías". Ahora bien, téngase en cuenta por lo que se refiere a la cuestión temporal, que esta "moda" de la ética de los negocios no es tan reciente, sino que viene calando lenta e imperceptiblemente nuestras mentalidades desde hace algunos años (Cfr. Ph. LE TOURNEAU (1996) "Existe-t-il une morale des affaires?", en AA. VV. (1996) La morale et le droit des affaires, París, pp. 7 ss.

${ }^{16}$ Vid. A. Comte-Sponville (2004) El capitalismo, ¿es moral?, op. cit. pp. 50ss.

$17 \mathrm{Cfr}$, si bien no con planteamientos similares, A. CORTINA ORTS (2006) "La responsabilidad social corporativa y la ética empresarial", en AA. VV. (2006) Mitos y realidades de la Responsabilidad Social Corporativa en España. Un enfoque multidisciplinar, Cizur Menor, p. 117-118, y A. ARGANDOÑA (2006) "Economía de mercado y responsabilidad social corporativa": Papeles de Economía Española, 108, p. 5.

${ }^{18}$ H. B. Acton (2002) La moral del mercado, op. cit., p. 24. 
Kant y a una de sus obras más relevantes, la Fundamentación de la Metafísica de las Costumbres [1785], ${ }^{19}$ de donde extraemos lo siguiente:

i) Una acción es moralmente valiosa cuando el motivo, no las consecuencias, está en el cumplimiento de un deber moral interno que nos viene de la razón.

ii) Ahora bien, no es suficiente que la acción sea conforme a la ley moral, porque si resulta coincidente con el interés propio o con cualquier otro motivo de inclinación (necesidades, deseos, preferencias, apetitos o incluso la compasión) carecerá ya de valor moral. ${ }^{20}$

iii) Para ejemplificar la diferencia entre el deber y las inclinaciones Kant recurre a la figura del comerciante, concretamente al que él denomina como un comerciante avispado (avisado o avezado), que sólo es honrado para conservar a sus clientes:

Por ejemplo, es conforme al deber, desde luego, que el comerciante no cobre más caro a un comprador inexperto, y en los sitios donde hay mucho comercio el comerciante avispado no lo hace, en efecto, sino que mantiene un precio fijo para todos en general, de forma que un niño puede comprar en su tienda tan bien como otro cualquiera. Así pues, uno es servido honradamente, pero esto no es ni mucho menos suficiente para creer que el comerciante haya obrado así por deber o por principios de honradez: lo exigía su provecho. Tampoco es posible admitir además que el comerciante tenga una inclinación inmediata hacia los compradores, de manera que por amor a ellos, por decirlo así, no haga diferencias a ninguno en el precio. Por consiguiente, la acción no ha sucedido ni por deber ni por inclinación inmediata, sino simplemente con una intención egoísta. ${ }^{21}$

Se trata de un sujeto de una honradez intachable, pero que como dice Kant, actúa conforme a la moral y conforme al deber, efectivamente, ¿̇y cuál es su deber? Ser honrado, y efectivamente es honrado y actúa conforme al deber, pero no por deber. Sino que actúa conforme al deber, pero por interés, porque de lo contrario dicho comerciante es plenamente consciente de que "la primera

\footnotetext{
19 I. KANT (2004) Fundamentación de la metafísica de las costumbres [1785] traducción castellana de L. Martínez de Velasco, Espasa-Calpe (Austral), Madrid, ${ }^{16} 2004$.

${ }^{20}$ Cfr. M. J. Sandel (2011) Justicia, Barcelona, p. 130.

${ }^{21}$ I. KANT (2004) Fundamentación de la metafísica de las costumbres, op. cit., p. 59.
} 
fullería descubierta le haría perder clientes" y por consiguiente dinero. Y bien, concluye Kant, en este caso, por conforme que sea a la moral, su acción carece de todo valor moral. Porque se realiza por interés, y lo propio del valor moral de una acción es el desinterés, no el interés. ${ }^{22}$

Lo anterior tiene como consecuencia que el deber moral quede oculto, solapado por el interés, hasta el punto de que se diluye y desaparece.

iv) La pregunta inmediata es: ¿̨qué sujeto actúa sin ningún tipo de inclinación? A lo que Kant nos responde con la figura del misántropo moral. ${ }^{23}$ De tal modo que la compasión del altruista merece elogio, pero no alta estima, porque sus actos corren parejos con otras inclinaciones, como por ejemplo el afán de honores. ${ }^{24}$ Sólo cuando consiga desasirse de esa inclinación y la realice sólo por deber, entonces y sólo entonces posee esta acción su verdadero valor moral:

Pero hay más aún: un hombre a quien la naturaleza haya puesto poca simpatía en el corazón; un hombre que, siendo por lo demás honrado, fuese de temperamento frío e indiferente a los dolores ajenos, acaso porque él mismo acepta los suyos con el don peculiar de la paciencia y fuera de resistencia, y supone estas mismas cualidades, o hasta las exige, igualmente en los demás; un hombre como éste (que no sería seguramente el peor producto de la naturaleza), desprovisto de cuanto es necesario para ser un filántropo, ino encontraría en sí mismo, sin embargo, cierto germen capaz de darle un valor mucho más alto que el que pueda derivarse de un temperamento bueno? iEs claro que sí! Precisamente en ello estriba el valor del carácter que, sin comparación, es el más alto desde el punto de vista moral: en hacer el bien no por inclinación sino por deber. ${ }^{25}$

${ }^{22}$ Cfr. A. Comte-Sponville (2004) El capitalismo, ies morale, op. cit., pp. 53-55, A. MAClNTYRe (2006) Historía de la ética, Barcelona, p. 209, J. Rawls (2007) Lecciones sobre la historia de la filosofía moral, Barcelona, pp. 228-231 y M. J. SANDEL (2011) Justicia, op. cit., pp. 130-131.

${ }^{23}$ Cfr. M. J. Sandel (2011) Justicia, op. cit., p. 133.

${ }^{24}$ Vid. I. KANT (2004) Fundamentación de la metafísica de las costumbres, op. cit., p. 60. Parece que hay aquí una visión amplia del interés que ya estaba presente en los moralistas franceses del siglo XVII, que concretamente vemos en La Rochefoucauld en sus Máximes [1666], cuando nos dice: "Por interés no entiendo siempre un interés relacionado con la riqueza, sino más frecuentemente uno relacionado con el honor o la gloria" (cfr. A. O. HIRSCHMAN (1978) Las pasiones y los intereses, México, p. 45 y también, D. COHEN (2013) Homo economicus, Barcelona, p. 140.

25 I. KANT (2004) Fundamentación de la metafísica de las costumbres, op. cit, pp. 60-61. 
Como nos dice Michael J. Sandel, ${ }^{26}$ parece que esta conclusión desafía a la intuición, y se pregunta: ${ }_{2}$ No es bueno, acaso, ser una de esas personas que disfruta ayudando a los demás? O dicho de otro modo, ¿̇cuándo, pues, tendrá una buena obra valor moral? Muy probablemente son estas dudas y la severidad del planteamiento kantiano lo que provoco en su momento las críticas de Schopenhauer, especialmente frente a lo sostenido por Kant, a favor de la compasión como fundamento de la moral y no la razón pura, así como que las emociones y los sentimientos animaban el instinto compasivo. ${ }^{27}$ Su crítica, nos dice Rüdiger Safranski, puede reducirse a dos aspectos: crítica a la sobrestimación de la razón en cuestiones de moral y crítica a la alianza secreta entre moral y egoísmo. ${ }^{28}$ De ahí desarrolla su ética de la compasión que ha sido denominada como una "mística práctica", una ética del "a pesar de", que aspira al menos a mitigar el dolor permanente. ${ }^{29}$ Un buen producto del romanticismo alemán. Pero estas ideas de la filosofía de la compasión se desvanecen en su ámbito más personal cuando Schopenhaver se enfrenta a las consecuencias de la revolución de $1848 .{ }^{30}$

Ahora bien conviene dejar constancia de lo siguiente. Por un lado, que ciertamente el filósofo romántico, en su crítica a Kant, ve el egoísmo por todas partes, en el deber, en la voluntad, e incluso, en la exigencia de universalidad del imperativo categórico, ${ }^{31}$ lo que sin duda resulta criticable o como poco excesivo. Pero es, por otro lado, lo que le lleva a descalificarlos porque el egoísmo representa el principal enemigo contra el que debe luchar el móvil moral. Y esto sí que resulta verdaderamente interesante para nosotros. De ahí que nos diga que las acciones

${ }^{26}$ Cfr. M. J. SANDel (2011) Justicia, op. cit., pp. 133-135.

${ }^{27}$ Así lo vemos en su Escrito concursante sobre el fundamento de la moral [1839-1840] (Los dos problemas fundamentales de la ética, con introducción y notas de Pilar LóPEZ DE SANTA MARÍA, Madrid, ${ }^{4} 2009$, especialmente pp. xxxii-xxxix y pp. 157ss.). Para una primera aproximación actualizada a esta visión crítica de Schopenhauer nos remitimos a J. RIFKIN (2010) La civilización empática. La carrera hacia una conciencia global en un mundo en crisis, Madrid, pp. 334-338. Para una aproximación más detallada puede verse R. SAFRANSKI (2011) Schopenhaver y los años salvajes de la filosofía, Barcelona, pp. 421-429.

${ }^{28}$ Cfr. R. SAfranski (2011) Schopenhaver y los años salvajes de la filosofía, op. cit., p. 421.

$29 \mathrm{lbi}$, p. 423-424.

$30 \mathrm{lbi}$, p. 424-429.

${ }^{31}$ Cfr. P. López de Santa María, "Introducción", en A. Schopenhauer (2009) Los dos problemas fundamentales de la ética (con introducción y notas de P. LóPEZ de SANTA MARía, Madrid ${ }^{4} 2009$, pp. xxix-xlii. 
de valor moral sólo pueden darse en ausencia de toda motivación egoísta. Y que a su juicio sólo existe un móvil moral auténtico: la compasión. Una compasión que desglosa en las dos virtudes éticas fundamentales: la justicia y la caridad. La primera, de grado inferior, consiste en no ofender a los demás, mientras que la segunda constituye un grado superior de la compasión, que incluye todas las acciones depuradas de cualquier motivación egoísta y supone una participación activa en la eliminación del sufrimiento del otro. En definitiva el distanciamiento con Kant resulta claro porque rechaza la fuerza de la razón como origen del deber moral (la "jeringa" del mero intelecto no podría darles nunca vida) y en su lugar apela a una fuerza impulsiva (los motivos) que la encuentra en la compasión, que por otra parte acaba ubicando en la voluntad y en el carácter. Un discurso contradictorio y un tanto irracional. ${ }^{32}$ Pero aún así, como decimos, lo que verdaderamente nos importa es comprobar la coincidencia de fondo con el argumento kantiano, esto es, que sea cual sea el fundamento de la acción moral, para que dicha acción tenga verdadero valor moral tiene que tratarse de una acción desinteresada. $O$ dicho de otro modo, son acciones que se contraponen a los impulsos del egoísmo; acciones que no tienen como objetivo el propio bien, ni siquiera por caminos indirectos: "rectitud voluntaria, puro amor del prójimo y auténtica nobleza de sentimientos". ${ }^{33}$

Pues bien, como también nos dice M. J. Sandel, ${ }^{34}$ cuando Kant acude a la figura del misántropo moral no es que nos lo quiera presentar como ejemplo moral, sino que lo usa como referente, como tipo en el sentido weberiano diríamos nosotros. En la práctica es frecuente que el deber y la inclinación coexistan. A veces nos cuesta a nosotros mismos determinar los motivos por los que actuamos, mucho más respecto a los demás. Esto es algo que Kant no lo niega. Y tampoco piensa que sólo un misántropo duro de corazón pueda realizar actos moralmente valiosos. En definitiva con la figura del misántropo lo que pretende es que quede bien claro el motivo del deber, y no dejar ninguna duda sobre que las buenas obras deben hacerse, nos agrade o no hacerlas, sin que queden solapadas por la simpatía o la compasión y sin atención a las consecuencias.

32 Cfr. J. J. SeBReL (2007) El olvido de la razón. Un recorrido crítico por la filosofía contemporánea, Barcelona, pp. 29-40.

${ }^{33}$ Vid. R. SAFRANSKI (2011) Schopenhaver y los años salvajes de la filosofía, op. cit., p. 422.

${ }^{34}$ Vid. M. J. SANDel (2011) Justicia, op. cit., p. 133-135. 
Por otro lado, respecto a la compasión, como nos recuerda Comte-Sponville, no es para Kant un deber, sino un sentimiento, que como tal se siente o no se siente, no se manda. Pero de la misma manera que sucede con el amor, ${ }^{35}$ la compasión se puede y se debe educar, porque es de esta manera como se podrá pasar de una cosa a la otra, del sentimiento al deber. De ahí que la compasión sea una virtud, porque es el puente que nos permite pasar del orden afectivo al orden ético, de lo que se siente a lo que se quiere, de lo que se es a lo que se debe. ${ }^{36}$

Las ideas anteriores de I. Kant, aunque resulte un tanto paradójico, las vemos en cierto modo anticipadas en la obra del padre del liberalismo económico, Adam Smith. Ciertamente no fueron expuestas por éste con la contundencia y claridad con la que las dio a conocer el filósofo alemán. Pero no obstante, si uno se aproxima a su obra en su conjunto, nos referimos especialmente a sus dos obras más relevantes, La Riqueza de las Naciones [1776] $]^{37}$ y La Teoría de los sentimientos morales [1759], ${ }^{38}$ nos encontramos con que existe una aproximación entre ambos pensadores. De hecho se habla por algunos autores contemporáneos de la más que probable influencia de la obra de A. Smith en algunos aspectos del pensamiento kantiano. ${ }^{39} \mathrm{Al}$ igual que en el alemán, el escocés separa ambos planos, el moral y el económico, de manera que la moral no puede integrarse en los negocios que se caracterizan claramente por el interés. Los comportamientos morales sólo pueden estar presentes allí donde brille el desinterés, donde la acción sólo esté guiada por un deber moral sin otros impulsos que la motiven.

No parece que quepan muchas dudas de que el economista parte del egoísmo o de la persecución del propio interés como causa de la riqueza, lo deja claro en el célebre párrafo de La Riqueza cuando alude a que no es la benevolencia del

\footnotetext{
${ }^{35}$ Cfr. A. Comte-Sponville (2005) El capitalismo, ¿es moral? (2005) Pequeño tratado de las grandes virtudes, Barcelona, p. 125.

36 Ibid.
}

${ }^{37}$ A. SМITH ( $\left.{ }^{6} 1990\right)$ Investigación sobre la naturaleza y causas de la riqueza de las naciones [1776], México, FCE.

${ }^{38}$ A. SMith (1997) Teoría de los sentimientos morales [1759] edición de C. RodríGuez Braun, Madrid.

${ }^{39}$ Vid. C. Rodríguez Braun (1997) "Estudio preliminar", en A. SMith (1997) Teoría de los sentimientos morales [1759], Madrid, p. 16, quien habla de una cierta influencia de A. Smith sobre Kant. En este mismo sentido se manifiesta más recientemente Amartya Sen que afirma con datos relevantes la más que probable influencia de A. Smith en Kant (cfr. A. SEN (2010) La idea de la justicia, Madrid, p. 153). 
carnicero...., la que nos procura el alimento, sino la consideración de su propio interés. ${ }^{40}$ No hay aquí alusión al deber moral, o a los posibles comportamientos desinteresados. ${ }^{41}$ Ahora bien no significa eso que no los reconozca o que no los admita, sino que los separa de los actos interesados, como ya lo había puesto de relieve diecisiete años antes en La Teoría de los sentimientos morales, cuando desde su inicio habla de la existencia en el hombre de unos principios que le hacen interesarse por la suerte de otros. ${ }^{42}$ De este modo distingue primero, por un lado, el plano moral descontaminado de egoísmo. Y más tarde, por otro, el plano económico, presidido por el interés. Aunque ya en la primera obra podemos comprobar que no realiza ninguna condena del egoísmo, bien cuando se refiere a las motivaciones de la conducta o bien a las virtudes y nos habla de que:

Es indudable que por naturaleza cada persona debe primero y principalmente cuidar de sí misma, y como cada ser humano está preparado para cuidar de sí mejor que ninguna otra persona, es adecuado y correcto que así sea. Por tanto, cada individuo está mucho más profundamente interesado en lo que le preocupa de inmediato a él que en lo que inquieta a algún otro hombre. ${ }^{43}$

O también cuando nos anticipa su idea sobre la sociedad de personas distintas como la de los comerciantes, regida por la utilidad y no por el amor o el afecto mutuo. ${ }^{44}$ Una idea que luego reitera en La riqueza, como hemos visto, y donde además añade que es falsa la pretensión de comerciar por razones de interés público: Jamás he sabido que hagan mucho bien aquellos que simulan el propósito de comerciar por el bien común. Por cierto que no se trata de una pretensión muy común entre los mercaderes, y no hace falta emplear muchas palabras para

${ }^{40} \mathrm{Vid}$. A. SMITH (6 1990) Investigación sobre la naturaleza y causas de la riqueza de las naciones, op. cit., p. 17.

${ }^{41}$ No obstante, Amartya Sen nos dice que en algunas escuelas de economía los lectores de Smith no parecen ir más allá de estos breves renglones, cuando en realidad sólo están dirigidos a una cuestión muy específica como es la motivación del intercambio económico, no la producción o la distribución, cuando en el resto de los escritos de Smith hay extensas discusiones sobre la función de otras motivaciones que influyen en la acción humana (cfr. A. SEN (2010) La idea de la justicia, Madrid, pp. 217-218). Con todo, a nuestro juicio, hay que decir que también en la producción y en la distribución lo que prima es la relación de intercambio.

${ }^{42}$ A. SMITH (1997) Teoría de los sentimientos morales, op. cit., p. 49.

43 Ibid, p. 180.

${ }^{44} \mathrm{Ibid}$, pp. 185-186. 
persuadirlos de ella. ${ }^{45} \mathrm{O}$ también cuando nos presenta al comerciante como un sujeto peligroso: las gentes del mismo oficio pocas veces se reúnen, aunque sea para divertirse y distraerse, sin que la conversación acabe en una conspiración contra el público o en algún arreglo para elevar los precios. ${ }^{46}$ Esto permite entender que las alabanzas al libre mercado del profesor de Glasgow no sean porque éste sirva especialmente a los empresarios ("capitalistas"), sino porque sirve al bien común, ya que estimula la creatividad, la audacia y el esfuerzo, además favorece los salarios altos, los precios bajos y las ganancias relativamente pequeñas, esto es, por resultados que beneficiarían a la mayor parte de la población: los trabajadores asalariados y los consumidores ${ }^{47} \mathrm{Y}$ de ahí que se pueda sostener que la comunidad saca provecho del lucro de los empresarios, si bien es cierto que no de manera voluntaria, sino de manera forzada por el Estado, porque es de este lucro individual de donde una comunidad inteligente y bien organizada, mediante el desarrollo de unas condiciones marco ventajosas para los empresarios prósperos, como obtiene a través de los impuestos los recursos necesarios para los proyectos comunes. Y esto es algo de lo que era consciente Smith, de la necesidad de una autoridad -el Estado- que sirva de contrapeso a las fuerzas del mercado y se oponga a las distorsiones de la competencia que de otro modo conducen a los oligopolios y a los monopolios, en beneficio y dominio de unos pocos y la explotación de muchos. ${ }^{48}$ El propio Kant, ${ }^{49}$ como nos recuerda Höffe, ${ }^{50}$ aboga por una competencia fuerte, porque de esta manera se evita que las fuerzas creadoras del hombre se adormezcan.

Adam Smith apunta este distanciamiento entre lo moral y lo económico, de manera que deja claro en La Teoría de los sentimiento morales que la aprobación

${ }^{45} \mathrm{Vid}$. A. SMITH (6 1990) Investigación sobre la naturaleza y causas de la riqueza de las naciones, op. cit., cit., p. 402.

${ }^{46}$ Cfr. M. SANTOS REDONDO (1997) Los economistas y la empresa. Empresa y empresario en la historia del pensamiento económico, op. cit., p. 39.

${ }^{47} \mathrm{Cfr}$. O. HöfFE (2007) Ciudadano económico, ciudadano del Estado, ciudadano del mundo. Ética política en la era de la globalización, Buenos Aires, pp. 37-38.

${ }^{48} \mathrm{lbid}$.

${ }^{49}$ Cuarto principio del opúsculo titulado Idea de una historia universal en sentido cosmopolita [1784] en I. Kant (1994) Filosofía de la historia, México, pp. 46-48.

50 Vid. O. Höffe (2007) Ciudadano económico, ciudadano del Estado, ciudadano del mundo. Ética política en la era de la globalización, op. cit., p. 39. 
moral no tiene nada que ver con el egoísmo, ${ }^{51}$ y lo hace especialmente para combatir las tesis utilitaristas más perturbadoras, como son las representadas por Mandeville [también de Hobbes] en su obra La Fábula de las abejas (o Los vicios privados hacen la prosperidad pública) [1729], ${ }^{52}$ que relacionaban claramente ambas cosas. Probablemente es cierto que en lo económico no existieran grandes diferencias entre el pensamiento de Smith y el de Mandeville, pero en lo moral sí que existe una clara diferencia, porque hay un gran esfuerzo en el primero por justificar moralmente lo que es bueno económicamente que le lleva a distinguir entre las pasiones exageradas e inmorales y las moderadas y permisibles. Y no se puede negar que esto lo aproxima algo a la visión escolástica, ${ }^{53}$ pero refleja más la influencia de los pensadores de su época como Hutcheson, ${ }^{54}$ de quien fue discípulo, con sus apreciaciones sobre el sentido moral y sobre que la acción buena es desinteresada, unos pensamientos que están en la raíz común de la ética de la llustración, y de los que el propio Kant se hace eco. ${ }^{55}$ Con todo hay que decir que posteriormente, en La Riqueza, como hemos visto, A. Smith se aparta de esa aparente visión de la economía como un caso de su teoría de la simpatía moral, para sentar el distanciamiento entre el interés y los sentimientos morales. De manera que a la teoría económica le basta con describir los actores, acciones, objetos, interacciones, la propiedad, el capital, margen crediticio, precios, etc. Esto es (lo cual al parecer irritaba a Marx), bastaba con hacer un balance de los costes de los materiales, del precio del dinero y de los costes laborales para saber si una empresa, bajo unas determinadas condiciones de mercado, iba a resultar rentable o no. ${ }^{56}$ De manera que la ética o la moral no jugaban un papel relevante, o dicho de otro modo, nos configura ya el sistema económico moderno despojado

${ }^{51}$ Cfr. V. MÉndez Baiges (2007) Adam Smith. Vida, pensamiento y obra, Pamplona, p. 101.

52 B. MANDEVILE (1997) La fábula de las abejas o Los vicios privados hacen la prosperidad pública, op. cit., con comentario crítico, histórico y explicativo de F. B. KAYE. A. Smith le dedica sus comentarios críticos en la Teoría de los sentimientos morales cuando se ocupa de los sistemas licenciosos (op.cit, pp. 536-544).

${ }^{53}$ Cfr. M. SANTOS REDONDO (1997) Los economistas y la empresa. Empresa y empresario en la historia del pensamiento económico, op. cit., p. 41.

${ }^{54}$ Cfr. A. O. HiRsCHMAN (1978) Las pasiones y los intereses, pp. 70-73.

${ }^{55}$ Cfr. N. BlıBeny, editor (2012) Textos clave de la ética, Madrid, pp. 300-302.

${ }^{56}$ Cfr. N. LuHmann (2013) "La ética económica, ¿̇es una ética?", art. cit., pp. 189-190. 
de las pasiones, ${ }^{57}$ claramente amoral, ${ }^{58}$ y por tanto, y esto es lo verdaderamente importante, distanciado de los anteriores planteamientos escolásticos. ${ }^{59}$

Frente a la descontaminación moral de lo económico, presidido por el interés propio, como según parece nos viene de A. Smith y así lo entiende una gran parte de la economía moderna, ${ }^{60}$ el profesor Amartya Sen intenta hacernos ver que el pensador escocés, en La Teoría de los sentimientos morales, pone cierto énfasis en el poder de las reglas establecidas de comportamiento, que no estarían confinadas a seguir necesariamente los dictados del amor (interés) propio, sino que reciben la influencia implícita de los argumentos morales. O dicho de otro modo, que a veces la conducta moral tiende a adoptar la forma del simple acatamiento de las convenciones establecidas. ${ }^{61}$ El pasaje smithiano de referencia es el siguiente:

Muchas personas se han comportando de modo sumamente decente y durante toda su vida han evitado cualquier grado apreciable de culpa, y sin embargo quizá no han experimentado nunca el sentimiento sobre cuya corrección nosotros fundamos nuestra aprobación de su conducta sino que actuaron siguiendo meramente lo que detectaron que eran las reglas de comportamiento establecidas. ${ }^{62}$

De aquí parece que se deduce por Amartya Sen que Smith no descarta la existencia de otras motivaciones distintas al interés propio en las acciones humanas, incluidas las acciones económicas. Hay que aclarar, primero, que de lo que estamos hablando es de las reglas generales de conducta, que se adquieren por la experiencia, y que según Smith constituyen el sentido del deber: un principio de sobresaliente importancia en la vida humana y el único principio por el cual la mayoría de la humanidad puede orientar sus acciones. ${ }^{63}$ Ahora bien, no se

${ }^{57}$ Cfr. A. O. HIRSCHMAN (1978) Las pasiones y los intereses, pp. 106-118.

${ }^{58} \mathrm{Cfr}$. A. Comte-Sponville, El capitalismo, ¿̇es morale, cit., p. 83 ss.

59 Para una visión del modelo escolástico nos remitimos a Sánchez Albornoz, N., "Estudio preliminar. Tomás de Mercado, entre la tradición escolástica y la práctica económica del Siglo de Oro", en T. DE MERCADO (1571) Suma de tratos y contratos, Sevilla, Clásicos del pensamiento económico español, Instituto de Estudios fiscales, Ministerio de Hacienda, Madrid, 1977, vol. 1, pp. XVIII-XXIX.

${ }^{60}$ Cfr. A. SEN, La idea de la justicia, op. cit., pp. 216-217.

${ }^{61} \mathrm{lbid}, \mathrm{pp} .217-218$.

${ }^{62}$ A. SMITH, Teoría de los sentimientos morales, op. cit., p. 296.

${ }^{63} \mathrm{lbid}$ 
puede uno quedar aquí. Es necesario, en segundo lugar, seguir avanzando en La Teoría de los sentimiento morales, unas páginas más adelante, y llegar al capítulo siguiente (sexto) de esta Parte III, donde se precisa con cierto detalle cuándo (en qué casos) el sentido del deber ha de ser el único principio de nuestra conducta y cuándo (en qué casos) han de concurrir también otras motivaciones. ${ }^{64} \mathrm{Y}$ nos dice aquí que la cuestión, si bien no puede resolverse con mucha precisión, depende de dos circunstancias, una, de lo agradable o desagradable del sentimiento o afecto que nos alejaría de las reglas de carácter general y, otra, de la precisión y exactitud o de la imprecisión e inexactitud de las reglas mismas.

Pues bien, respecto a lo primero, y en particular cuando se trata de las pasiones egoístas, esto es, del propio interés, hay que distinguir entre los casos en los que el interés propio es mínimo o insignificante (i) y aquellos otros en los que es relevante o extraordinario (ii): 65

i) En los casos normales, pequeños y vulgares, deben primar las reglas generales más que ninguna pasión por los objetivos mismos. Nos pone como ejemplo Smith que el anhelar o urdir tramas para conseguir o ahorrar un solo chelín degradaría al empresario más vulgar a los ojos de todos sus vecinos. En estos casos, por muy miserables que sean sus circunstancias, no debe aparecer en su conducta ninguna atención a tan insignificantes asuntos por los asuntos mismos, sino que deberá respetar la regla general y por tanto el estilo de comportamiento propio de todas las personas de su profesión.

ii) Por el contrario, en ocasiones más relevantes y extraordinarias seríamos torpes, insípidos e indecorosos si los objetivos mismos, esto es, el propio interés, no nos animarán con un grado de pasión notable. Una persona parecerá mezquina si no los persigue con algún ahínco por ellos mismos. Y entre los ejemplos que pone está de nuevo la figura de un empresario que será considerado poca cosa por sus colegas si no se afana por conseguir lo que ellos llaman un trabajo extraordinario, o un beneficio fuera de lo común. Porque ese espíritu animoso constituye la diferencia entre un hombre emprendedor y un hombre de sosa mediocridad. "Las grandes metas del propio interés, cuya pérdida o adquisición modifica bastante el rango de la persona, son los objetivos de la pasión propiamente denominada ambición, una pasión que cuando se mantiene dentro de las fronteras de la prudencia y la justicia es siempre admirada en el mundo."

\footnotetext{
${ }^{64}$ Ibid., p. 311 ss.

${ }^{65}$ Ibid., pp. 314-315.
} 
En cuanto a lo segundo, el grado en que nuestra conducta ha de proceder por entero de un respeto a las reglas generales dependerá en parte de la precisión y exactitud o de la imprecisión e inexactitud de las reglas mismas. ${ }^{66}$ Las pautas generales de todas las virtudes, nos dice Smith, son flexibles e imprecisas, abiertas a numerosas excepciones, quizá con la salvedad de la gratitud, pero especialmente con la salvedad de la justicia. Pues bien, es a causa de esta falta de precisión por lo que se generan situaciones de falsa conciencia, que dan lugar a seguir un erróneo sentido del deber. En estos casos puede ser que aparezca el sentido de humanidad, la compasión, que corrigen en parte el error, pero a pesar de todo, estos comportamientos no merecen el aplauso que le hubiese correspondido en el caso de una completa autoaprobación. Por que como termina diciendo Smith: "Ninguna acción puede con propiedad ser denominada virtuosa si no está acompañada por el sentimiento de la autoaprobación." ${ }^{67}$

De todo lo anterior, frente a la postura de A. Sen, se puede deducir que para Adam Smith los verdaderos asuntos económicos pueden y deben estar desprovistos de otras consideraciones que no sean el objeto mismo del propio interés, porque es la manera de poder alcanzarlos, si bien siempre dentro de las fronteras de la prudencia y de la justicia. Y por otro lado, que la moralidad de los actos, sólo es plena, cuando está guiada por el sentido del deber y cuenta con nuestra total autoaprobación, y no, como luego reiterará Kant, cuando está impulsada por otros motivos de inclinación.

En definitiva, para finalizar, si como vemos que $A$. Smith se limitó a apuntarlo, y se puede decir, a nuestro juicio, que incluso en cierto modo se anticipó al imperativo categórico kantiano mediante la figura del espectador imparcial y de la simpatía; 68 Kant, por su parte, va mucho más lejos y lo afirma con rotundidad en su camino hacia ese imperativo categórico [Actúa sólo conforme a aquella máxima de la que a la vez puedas querer que se convierta en una ley universal], hacia un deber moral incondicional, que se universaliza y que por esta misma razón pospone los intereses propios a los de los demás. ${ }^{69}$

\footnotetext{
66 Ibid., pp. 316-322.

67 Ibid., p. 322.

${ }^{68}$ Cfr. V. Méndez BalGes, Adam Smith. Vida, pensamiento y obra, op. cit., pp. 95-100.

${ }^{69}$ Cfr. M. J. SANDEL, Justicia, op. cit., p. 140.
} 


\section{La ética de la virtud y las éticas aplicadas: del relativismo a la pretensión regulatoria}

La ética de la virtud, a diferencia de la concepción kantiana de la moral como un sistema de reglas y del enfoque utilitarista centrado en los resultados, como nos dice Robert C. Solomon, ${ }^{70}$ no se plantea como un procedimiento para descubrir qué está bien o mal o qué curso de acción es preferible. Se centra por el contrario en la persona. Esta ética de la virtud tiene su origen en Aristóteles y más modernamente su defensor en Alasdair Maclntyre..$^{71}$ Con la ética de la virtud se evalúan las cualidades del carácter del actor, más concretamente dicha evaluación se produce por la práctica dilatada de sus acciones de un modo correcto. Y hacer lo correcto, esto es, actuar virtuosamente, es hacer exactamente lo que redunda en nuestro mejor interés. El hombre bueno es el que hace lo que debe hacer, y quien cumple con su deber es bueno. De este modo parece que el conflicto que hasta ahora hemos planteado entre la moral y el interés desaparecería, porque la ética de la virtud lo rechaza de plano.

Pero sobre estas ideas si bien hay que reconocer su mayor aproximación a la vida real, no obstante no se puede dejar de ver el alto riesgo que representan porque nos conducen directamente al relativismo, con todo lo que ello supone de pérdida de los valores universales que son sustituidos por valores alternativos. Aunque se piense en la universalidad como un punto de llegada, eso no la desmerece en sí misma, ni tampoco da valor a ciertas tradiciones morales. Y por otro lado, por lo que se refiere a la competencia de tradiciones morales como posible camino hacia la universalidad, no sólo se presenta como un camino tortuoso, ${ }^{72}$ que en cierto modo nos remonta a los tiempos pretéritos de La Reforma y La Contrarreforma, ${ }^{73}$ sino que además muy probablemente o no nos lleve a ninguna parte, y en este caso nos mantenga en el relativismo, o en el mejor de los casos nos conduzca a duras penas por la vía inductiva hacia el mismo destino ya propuesto desde hace tiempo

70 Vid. R. C. Solomon (2009) El pequeño libro de filosofía, tr. esp., Madrid, p. 114.

\footnotetext{
${ }^{71}$ A. MAClNTYRE (2001) Tras la virtud, Barcelona. Para una aproximación sucinta a la ética de la virtud puede verse J. M. DíAz Alvarez (2007) "La virtud", en La aventura de la moralidad (Paradigmas, fronteras y problemas de la ética), Madrid, pp. 405-443.
}

${ }^{72}$ Cfr. J. M. Díaz Alvarez (2007) "La virtud", en La aventura de la moralidad (Paradigmas, fronteras y problemas de la ética), op. cit., p. 433.

${ }^{73}$ Vid. H. Küng (2002) La Iglesia Católica, Barcelona, p. 149 ss., esp. 161-184. 
tanto por el universalismo aristotélico, como especialmente por el universalismo kantiano. En definitiva, a nuestro juicio, en todos estos planteamientos modernos parece que se intenta llevar a la ética más allá de sus propias posibilidades. La ética, o la moral, por principio, por universal, no parece fácil que pueda descender de lo general a lo particular, para eso está la justicia, o si se quiere mejor el derecho, ${ }^{74}$ que es lo que verdaderamente cuenta con el instrumental necesario para entrar en el entramado de la complejidad social y desarrollar y aplicar la virtud de la justicia. En este sentido estamos mucho más cerca de John Rawls y su Teoría de la Justicia (y por tanto también de Kant) cuando habla de los bienes primarios ${ }^{75}$ como medios de carácter general para la búsqueda de los propios fines, y que deja el resto de la tarea para la fase legislativa, que de otros, como Martha Nussbaum, que si bien defiende la universalidad aristotélica y combate el relativismo, intenta ir más allá con el desarrollo de su lista de virtudes transculturales. ${ }^{76}$

En cuanto a las éticas aplicadas, al parecer se desarrollan como un medio para recuperar la credibilidad y la confianza de las profesiones. Esto es, la forja del carácter de la profesión, que es la que garantiza su éxito a medio y largo plazo. ${ }^{77}$ Y a estos efectos se nos presentan como ejemplos El Código de Nüremberg de 1946, el caso Watergate como impulso de la ética de la empresa, o en el ámbito de la información, el código ético de los periodistas catalanes de 1992. Se pretende llevar la buena voluntad a las instituciones y a las corporaciones. Que el empresario, y los demás profesionales en sus quehaceres diarios no tengan que salir a combatir gigantes o molinos, sino construir unas actividades e instituciones que les permitan alcanzar las metas que les dan sentido. De esta forma se pasa de la ética a las <éticas>: ética de la empresa, cuando de existir debería ser del empresario, ética de la medicina, cuando debería ser del médico, ética de la biotecnología, ética de la información, ética de los medios audiovisuales, etc. Al final

${ }^{74}$ Cfr. V. CAmps y A. CoRtina, "Las éticas aplicadas", en La aventura de la moralidad (Paradigmas, fronteras y problemas de la ética), op. cit., p. 455. También A. Comte-Sponville, Pequeño tratado de las grandes virtudes, op. cit., pp. 71-72.

${ }^{75}$ Vid. J. Rawls (1985) Teoría de la justicia, México, p. 112 ss.

${ }^{76}$ Vid. M. Nussbaum, "Non-Relative Virtues: An Aristotelian Approach", en M. Nussbaum y A. Sen (eds) (1993) The Quality of Life, Oxford, Clarendon Press, p. 242 ss. También, por quien citamos, cfr. J. M. Díaz Alvarez, "La virtud", en La aventura de la moralidad (Paradigmas, fronteras y problemas de la ética), op. cit., pp. 433-439.

77 Cfr. V. CAmps y A. CoRtina, "Las éticas aplicadas", en La aventura de la moralidad (Paradigmas, fronteras y problemas de la ética), op. cit., pp. 447-449. 
hay tantas éticas o tantos tipos diferentes de moral que la ética y la moral acaban por diluirse y desaparecer. Tanto éxito de la ética se podría decir que puede dar lugar a su mayor fracaso.

Así se comprueba si nos atenemos al argumentario que se utiliza en defensa de estas éticas aplicadas, cuando para huir del relativismo y de los particularismos se sustenta en principios ciertamente universalizables, como lo son el respeto a la dignidad de la persona, la defensa de la autonomía individual, el imperativo de no hacer daño, etc. ${ }^{78}$ pero que precisamente por su reconocimiento universal no necesitan de mayor respaldo, aunque se pueda decir que nunca esté de más recordarlos. Es más, se trata por lo general de principios positivizados por el Derecho, incluso a veces con rango constitucional o cuasi constitucional. Pero lo que sucede de nuevo, a nuestro juicio, en cierta proximidad con la ética de la virtud, es que se está en trance de dar el salto de lo moral a lo jurídico, porque como se dice por sus propios defensores se pretende romper con la separación canónica entre la vida buena y la justicia. ${ }^{79}$ Y ello porque para las éticas aplicadas dicha separación es muy cuestionable, de modo que si lo bueno alcanza una relevancia moral eso quiere decir que no debe ser abandonado a decisiones estrictamente privadas. O dicho de otro modo, se reconoce que las éticas aplicadas pertenecen al mundo privado, pero no obstante se nos dice que la perspectiva de un <liberalismo moral> absoluto no podrá ayudar de ningún modo a que la sociedad sea más justa. Y la verdad es que esto suena bastante contradictorio, porque la moral y la política jurídico-legislativa, esto es, el derecho, aunque próximas, se mueven en planos distintos. ${ }^{80}$

Hay que recordar aquí que el derecho es fundamentalmente un instrumento de legitimación en sí mismo, sin perjuicio de que parte de esa fuerza legitimadora la venga recibiendo tradicionalmente de razones morales. ${ }^{81}$ De ahí que la moral o la ética no añadan mucho más cuando el derecho ocupa su lugar. En particular

\footnotetext{
78 Ibid., p. 455.

79 Ibid., p. 456.

${ }^{80}$ Cfr. A. Comte-Sponville, A., El capitalismo, ¿Es morale, op. cit., p. 62 ss. y 69 ss. También, A. ArtetA (2012) Tantos tontos tópicos, Barcelona, pp. 147-148.
}

Cfr. J. HABERMAS (1998) "Epílogo a la cuarta edición, revisada", en Facticidad y validez, Madrid, p. 648.

${ }^{81}$ Ibid., p. 659. 
el Derecho moderno tiene tras de sí la fuente de legitimación de un procedimiento democrático de producción del derecho. Dicho de otro modo, es el proceso democrático el que soporta toda la carga de la legitimación. ${ }^{82}$ De ahí que se pueda decir que la persistencia excesiva en el fundamento moral puede llegar a ser pernicioso, porque deja en evidencia la fuerza de la ley que se debe legitimar por sí misma. Y podría dar la impresión de que el Derecho positivo queda subordinado a la moral, algo que en principio no debe suceder. ${ }^{83} Y$ no debe suceder, porque con el reconocimiento de los derechos subjetivos, como se nos dice, el derecho moderno otorga generalidad al principio de que <está permitido todo lo que no está prohibido>. A lo que hay que añadir que el derecho no se agota en las cuestiones morales, sino que tiene una estructura más compleja que la moral y abarca aspectos empíricos, pragmáticos, éticos y de ponderación equitativa de intereses. Hay otros discursos, además del moral, que deben ser tenidos en cuenta. El derecho se constituye así en un complemento funcional de la moral, porque con el derecho se compensan las debilidades funcionales de una moral de contenidos un tanto indeterminados e inseguros. $Y$ sin que eso signifique la neutralidad moral del derecho, dado que las razones morales penetran a través del proceso democrático de producción legislativa. ${ }^{84}$

Pues bien, una vez que a la pretensión de legitimidad de las normas jurídicas se la deja de identificar, bajo el apelativo de la corrección, ${ }^{85}$ con la pretensión de justicia moral, según nos dice J. Habermas, ${ }^{86}$ el derecho positivo resultado de un proceso formal constituye el medio adecuado para dar salida a las diferentes expectativas de comportamiento. Y no parece que las sociedades complejas cuenten con ningún equivalente funcional capaz de sustituirlo. A lo que añade, y es lo que resulta de especial interés para nosotros, que:

La filosofía se mete en una tarea innecesaria cuando trata de demostrar que no sólo resulta obvio por razones funcionales, sino que también es una obligación moral organizar la convivencia en forma de derecho, es decir, el formar comunidades jurídicas. A los filósofos debería bastarles con que en las sociedades complejas sólo en el medio del

\footnotetext{
82 Ibid., p. 648.

83 Ibid., p. 648 ss.

84 Ibid., pp. 650-651, esp. en Facticidad y validez, op. cit., pp. 225-236, 381 ss.; también "Derecho y moral", en Facticidad y validez, op. cit., pp. 555-562 y 584-587.

${ }^{85}$ Cfr. R. Alexy (2005) La institucionalización de la justicia, Granada, pp. 55-67 y 82-87.

${ }^{86}$ Vid. J. HABERMAS, "Epílogo a la cuarta edición, revisada", en Facticidad y validez, op. cit., p. 659.
} 
derecho es ya posible establecer fiablemente esas relaciones de respeto mutuo (también entre extraños) moralmente obligatorias.

Otra cosa es que los argumentos morales se constituyan en las bases de la legislación futura. $Y$ sobre esto en principio nada hay que objetar. Pero también es cierto que no constituye ninguna novedad, ni tampoco es necesario para justificar esta función en los distintos ámbitos de la actividad humana el desarrollo de las denominadas éticas aplicadas, porque como decimos la moral de siempre viene cumpliendo esa función legitimadora y enriquecedora del Derecho. ${ }^{87}$ No obstante, desde las éticas aplicadas se aboga por la necesidad y la utilidad de los códigos éticos o guías de buenas prácticas para articular el desarrollo de estas éticas aplicadas. ${ }^{88}$ Y sobre el contenido de dichos códigos se reconoce que su aporte puede ser nulo, en el sentido de que se limitan a reiterar en muchos casos lo que el derecho positivo ya establece, con el agravante de que la norma ética obliga sólo en conciencia frente al carácter coactivo de la norma jurídica. Con todo se apunta que los códigos éticos cumplen alguno de los siguientes cometidos: recuerdan o enfatizan los principios básicos, se adelantan a una posible legislación o bien recomiendan maneras de hacer que no están reglamentadas jurídicamente. $Y$ en este sentido se puede decir que estos códigos o cartas éticas pueden ser útiles porque pueden mejorar la cohesión del grupo, pero hay que reconocer que se trata sólo de una herramienta para la mejor gestión interna y externa, pero eso no permite que se puedan llegar a calificar como la conciencia moral del grupo ${ }^{89} \mathrm{La}$ moral es sólo de los individuos, de ahí que la personalidad del empresario o de sus directivos, o de los profesionales, pueda influir en la empresa o en el colectivo profesional, pero no se puede deducir de aquí que la empresa es moral o que lo sea la profesión en su conjunto, sino que lo serán determinados sujetos en particular. Porque de no ser así acabaríamos teniendo tantas éticas o morales como profesiones y empresas, frente a la idea kantiana de una moral sino universal sí al menos universalizable.

\footnotetext{
${ }^{87}$ Cfr., recientemente, A. SEN, La idea de la justicia, op. cit., pp. 393-396, en claro distanciamiento con las tesis utilitaristas de Bentham y con aproximación y acogimiento de las ideas de Hart sobre la incorporación de la moral al derecho a través del reconocimiento nacional e internacional de los derechos humanos.
}

${ }^{88}$ Vid. V. CAmps y A. CoRtina, "Las éticas aplicadas", en La aventura de la moralidad (Paradigmas, fronteras y problemas de la ética), op. cit., pp. 458-459.

${ }^{89}$ Vid. A. Comte-Sponville, El capitalismo, ¿̇es morale, op. cit., pp. 189 ss. y 230. 


\section{La moral no es un buen instrumento para gobernar la em- presa: la búsqueda de la reputación y los códigos éticos}

En definitiva la moral que pueda aparecer no surgirá autogenerada por el propio mercado, no debe ser así, y cuando se ha pretendido el fracaso ha sido mayúsculo, como ha sucedido con el socialismo marxista-colectivista, sino que deberá proceder del exterior. ${ }^{90} \mathrm{El}$ mercado funciona sobre la base de un juego de intereses, intercambio de bienes y servicios, que derivan en comportamientos no necesariamente generosos o caritativos, aunque sí pueden ser calificados de solidarios; mientras que la moral constituye un catálogo de deberes personales que no entran en juego por interés, sino de manera desinteresada, por tanto al margen del mercado. Ahora bien, esto no impide, que cualquier empresario o directivo pueda tomar decisiones amparado o empujado por sus convicciones morales, sin duda que lo pueden hacer. Decisiones tales como no despedir, cuando deberían hacerlo bien por razones internas o externas a la empresa; o bien gastar más de lo exigido por la ley en la protección del medio ambiente; o comprar mercancías a un proveedor inadecuado para ayudarle a salir de su crisis empresarial; o vender sus productos a una ONG por debajo del precio de coste; $;{ }^{91}$ o no deslocalizar a tiempo una empresa para preservar los puestos de trabajo; o en fin, contratar como empleados a personas necesitadas pero a todas luces incompetentes $o$ inadecuadas para la realización de las labores a las que están destinados; o contratar más personal del necesario, etc. Y así podríamos seguir en una larga lista casi interminable de lo que la lógica del mercado desaconseja, por mucho que la moral individual pondere este tipo de decisiones. No obstante, no se puede negar que en ciertos casos, las empresas que adoptan alguno de estos comportamientos pueden obtener algún tipo de beneficio, como puede ser el evitar la publicidad negativa, o bien conseguir una mayor calidad de la mano de obra que atraen, seducida como es natural por el marchamo de empresa socialmente responsable. ${ }^{92}$

Pero sea como sea, lo verdaderamente importante, y sobre lo que hay que insistir, es que los directivos de una empresa que se precie no deben regirse como regla

\footnotetext{
90 Cfr. A. Comte-Sponville (2004) El capitalismo, ¿es morale, Barcelona, pp. 93-96. También puede verse, G. PeCES-BARBA (1993) Ética pública y Derecho, Real Academia de Ciencias Morales y Políticas, Discurso de recepción, Madrid, p. 29.

${ }^{91}$ Aquí la cuestión es delicada, porque se podría estar infringiendo el art. 17 de la Ley de competencia desleal. Cfr. J. Massaguer (1999) Comentario a la LCD, Madrid, p. 495 ss.
}

${ }^{92}$ Cfr. J. E. Stıgutz (2006) Cómo hacer que funcione la globalización, Madrid, p. 255. 
general por este tipo de comportamientos caritativos, porque los días de la empresa estarían contados, se estarían tirando piedras contra su propio tejado. La pregunta inmediata sería la siguiente: ¿̇cómo se podría hablar en estos casos de empresas sostenibles, entendidas como empresas de presente y futuro?, ,3 cuando lo más probable es que tales decisiones empresariales las aboquen a su desaparición. Luego en definitiva, en buena lógica, no es muy probable que los empresarios o sus directivos actúen de este modo, porque se trataría de comportamientos claramente suicidas desde el punto de vista empresarial.

Y si lo anterior es correcto, si la lógica del mercado nos dice que la ética o la moral no deben gobernar la empresa, sino que debe regirse, por supuesto siempre con fidelidad a la ley, por los principios y directrices propios de la ciencia económico-empresarial, no se acierta a entender del todo cómo es posible que en los momentos actuales se alardee tanto, y por tantos, de las bondades de la ética empresarial (versión empresarial del retorno de la moral), o de lo que es lo mismo de la RSC/RSE, para resolver los males que presuntamente acechan a las empresas o al entero sistema capitalista. ${ }^{94}$ Bien parece que lo que se pretende es transformar los problemas económicos (orden técnico-científico) y, especialmente, los político-jurídicos en <simples> cuestiones morales. Cuando en realidad no hace falta dar muchas vueltas a la cabeza para entender que la moral no puede resolver ni los unos ni los otros. Sobre los primeros no hay que insistir mucho, porque la cuestión es meridiana; pero sobre los político-jurídicos hay que insistir, porque puede existir - de hecho existe- cierta inclinación a pensar que, efectivamente, la moral puede sustituir al Derecho y a la Política. Nada más lejos de la realidad, se trata de un error tremendo en el que no debemos caer, porque nos estaríamos engañando a nosotros mismos y es la mejor manera de no resolver nunca ni los problemas económicos ni los político-jurídicos. ${ }^{95}$

\footnotetext{
${ }^{93} \mathrm{Cfr}$. A. SEN, La idea de la justicia, op. cit., p. 278 ss., que alude a las necesidades de las generaciones presentes y futuras, pero que va más allá de los niveles de vida y de "nuestros intereses", para abarcar la preservación, y si es posible la extensión, de las libertades y capacidades sustantivas de la gente hoy sin comprometer la capacidad de las futuras generaciones de tener una libertad igual o mayor. También puede verse M. A. RodRíGuez en Real Academia de Ciencias Económicas y Financieras, dir. A. OlCESE SANTONJA (2007) La Responsabilidad Social de la Empresa (RSE). Propuesta para una nueva economía de la empresa responsable y sostenible, Madrid, p. 102 ss. (www racef.es).
}

${ }^{44} \mathrm{Cfr}$. A. Olcese Santonja en Real Academia de Ciencias Económicas y Financieras, dir. A. Olcese SANTONJA (2007) La Responsabilidad Social de la Empresa (RSE). Propuesta para una nueva economía de la empresa responsable y sostenible, Madrid, p. 35 ss., esp. 45 ss. (www racef.es).

95 Vid. A. COMTE-Sponville (2004) El capitalismo, ¿es morale, Barcelona, p. 127: "Si se confía en que los Restaurantes del Corazón venzan la miseria y la marginación, si se confía en que el humanitarismo 
La única explicación posible, o al menos la más plausible a nuestro juicio, es que con esta avalancha en los últimos años de ética empresarial, o si se quiere de RSC/RSE, se pretende fundamentalmente dos cosas. Por un lado, mejorar la imagen pública de las empresas, especialmente de las grandes corporaciones, que como es sabido se ha visto deteriorada últimamente a consecuencia de los grandes escándalos protagonizados especialmente por empresas norteamericanas (Enron, Arthur Andersen, WorldCom, Adelphia, Global Crossing, Tyco, etc.), ${ }^{96}$ aunque no sólo de este país (en Italia el caso Parmalat). Se habla en estos casos de la responsabilidad social como un instrumento para el fomento de la reputación empresarial. Por otro lado, y esto nos parece mucho más preocupante, es que la RSC/RSE, al igual que las éticas aplicadas, ${ }^{97}$ guardan en sí mismas un alto componente autoregulatorio, dado su carácter voluntario, que por lo general sólo responden a intereses corporativos. En este caso, los Códigos éticos o las guías de buenas prácticas, sin perjuicio de una cierta utilidad, tienen por finalidad primordial la de evitar la aprobación de disposiciones legales más severas; o en todo caso, preservar el monopolio profesional que siempre será más flexible que una reglamentación jurídica. ${ }^{98}$ Algo de esto nos dice en la actualidad Peter Sloterdijk, ${ }^{99}$ cuando a propósito de la sociología del saber, y respecto al pensamiento de Max Scheler, nos recuerda que fue este autor el primero que a comienzos del siglo XX puso de manifiesto en sus estudios sobre sociología del saber la ligazón insuperable de los conocimientos a los intereses. Y como la expresión del <interés> constituye desde el siglo XVII un seudónimo civil de las pasiones, probablemente esto último de la mano de La Rochefoucault y también de Hobbes. ${ }^{100}$

sustituya a la política exterior, en que el antirracismo reemplace a la política de inmigración, es que uno se engaña a sí mismo".

${ }^{96}$ Cfr. J. C. Bogle (2007) La batalla por el alma del capitalismo, Madrid-Barcelona, pp. 47-93; J. E. Stigutz (2003) Los felices 90. La semilla de la destrucción, Madrid, p. 287 ss.

97 Cfr. V. CAmps y A. CoRtina, "Las éticas aplicadas", en La aventura de la moralidad (Paradigmas, fronteras y problemas de la ética), op. cit., p. 460.

${ }^{98}$ Cfr. S. MONNIER (2005) Les Comités d'éthique et le Droit. Eléments d'analyse sur le systéme normatif de la bioéthique, París, pp. 91-93; A. Cabanillas SánChez y J. Zavala (2008) "El principalismo y su influencia en la normativa española sobre investigación biomédica", en Libro Homenaje a Gregorio Peces-Barba, Madrid, v. I, p. 227 ss.

99 Vid. P. SLOTERDIJK (2013) Muerte aparente en el pensar. Sobre la filosofía y la ciencia como ejercicio, Madrid, pp. 126-127.

100 Cfr. A. HiRsCHMAN (1978) Las pasiones y los intereses, México, pp. 38 ss. y 49 ss. 
Como muy bien nos dice Ferrajoli respecto al mercado, éste constituye una sociedad natural, tanto más legítima y eficiente cuanto más expresiva de la absoluta autonomía individual, por lo que resulta inverosímil que las reglas y límites al mismo puedan provenir de su propio interior; algo que además resulta inconcebible dado que el mercado es el producto de las voluntades individuales de millones de personas, cada una de las cuales es portadora únicamente de su propio interés protegido por los respectivos derechos potestativos. De ahí que la introducción de límites autorregulatorios en interés de todos, incluido el propio mercado, nunca podrán venir de las empresas particulares que parten de una lógica y de una vocación natural e institucionalmente sólo acumulativas; lo que hace necesario la existencia de normas ordenadoras, y en particular <<reglas jurídicas >> heterónomas. ${ }^{101}$ Máxime si como se ha comprobado en multitud de ocasiones los organismos de autorregulación, o no cumplen su función, o incluso llegan a estar en connivencia con los poderes que deberían controlar. ${ }^{102}$

En definitiva, como se ha dicho desde un planteamiento nada sospechoso como es el caso del comunitarismo:

Los mercados no pueden quedar liberados del control público y de la regulación. Se puede confiar, hasta cierto punto, en la autorregulación del mercado, por ejemplo, a través de un acuerdo por el que las empresas se comprometan a no influir con su publicidad en el comportamiento de los niños más pequeños. Y las comunidades pueden desempeñar el papel de garantes de que eso se cumpla. Por ejemplo, muchas asociaciones de consumidores juegan un importante papel como guardianes informales del comportamiento de las empresas. Pero la experiencia demuestra que la última responsabilidad efectiva para evitar los excesos del mercado debe recaer en el estado. Con el fin de asegurar que la regulación del mismo no sea excesiva, las normas estatales se aplicarán solamente si queda demostrado que no resultan innecesariamente restrictivas con el mercado o que no pueden sustituirse por regulaciones mejores o por otros modos de conseguir los mismos propósitos sociales. ${ }^{103}$

Pero hay aquí además dos problemas añadidos, con un ámbito mucho más general, y claramente interrelacionados. Por un lado, la crisis de la ley o de las <transformaciones > de la misma, que ha dado lugar al desarrollo-especialmente por influencia anglosajona- del paraderecho o en terminología inglesa Soft Law, con una directa

101 Vid. L. FerRajou (2011) Principia iuris. Teoría del derecho y de la democracia. 2. Teoría de la democracia, Madrid, pp. 246-247.

102 Cfr. E. Vitale (2012) Defenderse del poder. Por una resistencia constitucional, Madrid, p. 100.

103 A. Etzıoni (2001) La tercera Vía hacia una buena sociedad. Propuestas desde el comunitarismo, Madrid, p. 81. 
conexión con la temática de la globalización. ${ }^{104}$ Y por otro, desde un punto de vista todavía más general, esta problemática se puede enmarcar dentro de la crisis del Estado de derecho, ${ }^{105}$ o de la transformación del Estado, ${ }^{106}$ especialmente, como nos dice J. Habermas, por el peligro real que existe de deslegitimación del Estado democrático respecto a la producción del Derecho. Pero respecto a esta cuestión como uno se puede imaginar estamos ante una problemática de un nivel superior y en la que por tanto no podemos ni debemos entrar.

\section{El mayor deber social de las empresas es obedecer las leyes y pagar los impuestos que el gobierno impone: un principio ético básico}

\section{Como nos dice Adair Turner:}

[C]uanto más esperamos civilizar al capitalismo con vagas admoniciones a la responsabilidad empresarial y la ética comunitaria, más nos apartamos de la identificación y la puesta en marcha de esas intervenciones específicas (redistribución, oferta de bienes colectivos o regulación) que harían más humano el capitalismo.

Porque hay que partir de que

[E]l mayor deber social de las empresas es obedecer las leyes y pagar los impuestos que el gobierno impone". 107

Y esto es congruente con la moral, porque la obediencia y el respeto a la ley formalizada constituye uno de los preceptos éticos más importantes. ${ }^{108}$

\footnotetext{
104 Una aproximación a estas cuestiones puede hacerse por medio del libro del profesor F. J. LAPORTA (2007) El imperio de la ley. Una visión actual, Madrid, pp. 243-265, donde se ocupa del imperio de la ley y globalización.
}

105 Cfr. J. Habermas, Facticidad y validez, op. cit., pp. 512-532.

106 Vid. I. Sotelo (2010) El Estado social. Antecedentes, origen, desarrollo y declive, Madrid, p. 324 ss.

107 Vid. A. TURNER (2003) Capital justo. La economía liberal, Barcelona, p. 356.

${ }^{108}$ Cfr. E. Fernández García (1987) La obediencia al Derecho, Madrid, esp. p. 167 ss.; J. M. Buchanan (2009) Los límites de la libertad. Entre la anarquía y el Leviatán, Madrid, p. 177. 
Resulta enormemente contradictorio apelar por un lado a la libre empresa y por otro a cierto sentimentalismo moral. Y es por esto por lo que se habla de la extraña paradoja de la denominada Tercera Vía, y en cierto modo del social-liberalismo, que optan por abandonar el liberalismo económico propio del Estado social, en beneficio de un cierto sentimentalismo más moralizante que moral, porque trata de imponer a la gente que sea más cuidadosa y más humana individualmente. ${ }^{109}$ Lo que resulta claramente contradictorio. Algo muy similar es lo que sucede con la stakeholder theory, que también ha dado lugar a que se hable de una paradoja respecto a la misma, porque resulta muy contradictorio para los gestores empresariales respetar una lealtad multifiduciaria que acaba poniendo en cuestión el derecho de propiedad de los accionistas. ${ }^{110}$

Sobre esta difícil cuestión de integración de la moral en el negocio mercantil hay que recordar que se trata de una vieja cuestión medieval, que dio lugar a un profundo debate entre los canonistas y juristas de la época, y que en buena medida fue resuelto con la integración de la moral cristiana en la ley. De esta manera la Ley se constituye en un puente entre la actividad mercantil y la salvación del alma. ${ }^{11}$ Por tanto el camino para llevar al mercado los postulados éticos o morales parece que deber ser el de la Ley y no la apelación a un sentimentalismo moralizante. La moral es útil y necesaria, pero su poder en una sociedad compleja es muy limitado. La complejidad social supera en mucho a la moral, de ahí que el Derecho que cuenta con una estructura más compleja (aspectos empíricos, pragmáticos, éticos y de ponderación equitativa de intereses) sea el instrumento idóneo para gobernar una sociedad, bien sea por medio de leyes o bien por las buenas costumbres.

\section{Conclusión: "el poder de la moral será siempre precario”}

No obstante, sin perjuicio de nuestras críticas, que entendemos justificadas, no queremos terminar sin realizar un pequeño canto a la esperanza. La ética empresarial - la RSC/RSE no son enteramente negativas, tienen el enorme mérito de llamar la atención del mundo económico sobre algunos valores esenciales, especialmente

109 Vid. A. TURner (2003) Capital justo. La economía liberal, Barcelona, pp. 358-359.

110 Vid., K. E. GOODPASTER (1991) "Business ethics and stakeholders analysis", Business Ethics Quarterly, 1(1), pp. 53-73.

111 Vid. H. J. Berman (1996) La formación de la tradición jurídica de Occidente, México, p. 355. 
sobre la dignidad del hombre. ${ }^{112}$ Hay aquí una clara aproximación a los postulados de la denominada Tercera Vía y del comunitarismo y su búsqueda de la buena sociedad, cuando hablan de que las personas deben ser tratadas como fines en sí mismas y no como meros instrumentos. ${ }^{113}$ Pero debemos ser realistas, como por otra parte nos enseñaron los sofistas, ${ }^{114}$ y la realidad nos pone de manifiesto, que hoy en día, como nos dice el prof. Stiglitz, ${ }^{115}$ todas las empresas, incluso las que más contaminan y las que peor tratan a sus trabajadores, contratan los servicios de empresas de relaciones públicas que aireen su sentido de la responsabilidad y su preocupación por el medio ambiente y por los derechos de los trabajadores. Hasta el punto de que las corporaciones se han hecho adeptas a la manipulación de la imagen y han aprendido a hablar en favor de la responsabilidad social al tiempo que continúan soslayándola. De manera que -nos sigue diciendo-, por importante que pueda ser el movimiento de la RSE no es suficiente, hay que completarlo con una normativa más dura. Las empresas realmente comprometidas darán la bienvenida a las regulaciones que refuercen el código de conducta que apoyan en público, porque las protegerán de la competencia desleal de las que no se suman a la misma política y contribuirá a evitar que haya una carrera de mínimos. Y en este sentido se hacen una serie de sugerencias legislativas. Por un lado, se sugiere limitar el poder de las corporaciones por medio del Derecho de la competencia, especialmente frente a la globalización de los monopolios, con una ley de competencia global y una autoridad global que la aplique. En este caso los modelos a seguir los constituyen el Derecho norteamericano y el Derecho europeo. Por otro, mejorar la gestión de las corporaciones, clarificando las obligaciones y las consiguientes responsabilidades de los administradores sociales, para que sepan a que atenerse, por ejemplo, en orden a la aplicación de las políticas de protección del medio ambiente incluso a costa de los beneficios distribuibles. Y en este mismo ámbito, responsabilizar a los ejecutivos de las empresas por sus acciones dañinas, dentro o fuera de la empresa, incluso con sanciones penales, a la vista de la ineficacia incentivadota para los gestores de las sanciones civiles,

\footnotetext{
112 Vid. Ph. LE TOURneau (1996) "Existe-t-il une morale des affaires?", en AAVV, La morale et le droit des affaires, Paris, p. 23.
}

113 Vid. A. ETzIONI (2001) La Tercera Vía hacia una buena sociedad. Propuestas desde el comunitarismo, Madrid, p. 15 ss.

114 Cfr. R. TARnAS (1997) La pasión del pensamiento occidental. Para la comprensión de las ideas que modelaron nuestra cosmovisión, Barcelona, pp. 41-47.

${ }^{115}$ De quien tomamos lo que sigue (Vid. J. E. StIGutz (2006) Cómo hacer que funcione la globalización, Barcelona, p. 241 ss., esp. 255 ss.). 
que quedan diluidas por el juego de las contramedidas negociadas con la propia empresa: la contratación de seguros que cubren incluso las posibles multas a los administradores.

En este punto un avance notable viene dado por la Ley Sabarnes-Oxley, aprobada por los Estados Unidos en 2002, bien que como reacción a los escándalos financieros ocurridos, pero con la clara finalidad de imputar al director general de la empresa la responsabilidad por la llevanza de la contabilidad. No menos importante, también en este ámbito de la gestión de las empresas, es lo relativo a que las corporaciones acaben reparando los daños producidos, ya sea a sus trabajadores $\mathrm{o}$ al entorno. En este punto las leyes tienen que mejorar mucho. Ya sea para permitir que el dañado pueda demandar a la empresa dañante en el país donde se encuentra la sede de la corporación, y así solventar la probable insolvencia de la filial. O ya sea facilitando la ejecución de sentencias extranjeras en los países desarrollados. Algo similar a lo que sucede en el caso de los arbitrajes comerciales internacionales. Y también, sometiendo a las firmas a los tribunales de los países donde desarrollan su actividad y cometen las infracciones.

En resumidas cuentas se hace necesario contar con una legislación internacional y con la creación de tribunales de justicia internacionales, leyes globales para una economía global, que permitan las demandas conjuntas de los consumidores o de los colectivos perjudicados, bien por razones de competencia o bien por razones de daños. De la misma manera que hace falta atacar sin remilgos, igualmente con leyes, la corrupción y los sobornos (y el secreto bancario), ${ }^{116}$ ya sea en su forma tradicional, o en la más moderna de los fondos para contribuciones de interés especial destinados a los partidos políticos, legisladores o funcionarios del gobierno a cambio de un trato especial. Por que pocas cosas resultan más corrosivas que la corrupción de las instituciones públicas, que permite la concentración de poder, que aquellos que detentan el poder económico se hagan también con el poder político. Amitai Etzioni nos llama la atención a los europeos, respecto a la pérdida de confianza social entre el público y especialmente respecto a los líderes públicos en los Estados Unidos:

El público norteamericano ha acabado por mostrarse particularmente cínico respecto a un sistema político en el que limitar el papel que juegan en la vida pública las aportaciones económicas privadas es casi imposible. Las sociedades europeas deberían prestar mayor

\footnotetext{
116 "Cuando permite ocultar infracciones, el cacareado secreto bancario ya no tiene nada de legítimo, pues la ética no debe servir para proteger el fraude fiscal, el dinero del crimen o el del terrorismo" $(G$. LIPOVETSKY (2003) Metamorfosis de la cultura liberal. Ética, medios de comunicación, empresa, Barcelona, p. 95).
} 
atención a esta cuestión de la que han dedicado hasta ahora. Es cierto que los problemas pueden ser considerados como menos graves en los países de la UE que en muchas otras sociedades, pero también es cierto que <el mejor momento para echar la llave a la granja es antes de que nos roben los caballos>. En Europa hay abundantes normas legales que pretenden impedir la corrupción de los políticos. Queda por ver si ello es suficiente para proteger la vida pública frente a la presión del poder económico privado. ${ }^{117}$

A pesar de todo, el movimiento por la responsabilidad social de la empresa hace concebir esperanzas a personas como el Nobel de Economía Joseph E. Stiglitz, porque son cada vez más las empresas que no quieren embarcarse en una carrera de mínimos y apoyan las leyes contra la corrupción. ${ }^{118} \mathrm{O}$ a otros, como Gilles Lipovetsky, les hace decir que a la ética de los negocios no se le puede exigir el desinterés, un virtuosismo imposible de llevar a cabo en el mundo económico, sino tan sólo el respeto de los principios más elevados del humanismo moral. Una ética modesta, pero que no equivale a una ética débil o nula, porque no podemos esperar más que eso del maridaje de la ética con los negocios. ${ }^{119}$

117 A. Etzioni (2001) La Tercera Vía hacia una buena sociedad. Propuestas desde el comunitarismo, Madrid, p. 93.

118 J. E. Stigutz (2006) Cómo hacer que funcione la globalización, Barcelona, pp. 267-268.

119 G. LIPOVETSKY (2003) Metamorfosis de la cultura liberal. Ética, medios de comunicación, empresa, Barcelona, p. 96. 